\title{
ASSOCIATION OF SKIPPING BREAKFAST ON NUTRITIONAL STATUS OF ADOLESCENTS IN SELECTED SECONDARY SCHOOLS IN OPI, NSUKKA LOCAL GOVERNMENT AREA, ENUGU STATE, NIGERIA
}

\author{
Onodugo, N.G., Nnadi, I.M., ${ }^{2}$ and Wilfred, Z.E., ${ }^{3}$ \\ Department of Nutrition and Dietetics, University of Nigeria, Nsukka
}

Corresponding author's email address: gift.onodugo@unn.edu.ng

\begin{abstract}
Background: Although breakfast meal has been regarded as the most essential meal for the day because it improves both the nutritional status and academic performance, research findings have demonstrated that skipping of meals was prevalent among group of individuals.

Objective: Association of skipping breakfast on nutritional status of adolescents in selected secondary schools in Opi, Nsukka Local Government Area, Enugu State, Nigeria.

Materials and methods: A cross-sectional survey design was employed in conducting this study. The study was conducted in Opi, a town in Nsukka Local Government Area of Enugu State in South-Eastern Nigeria. Multistage random sampling technique was used in selecting 210 secondary school students involved in the study. The collection of data included the use of a structured questionnaire; measurement of anthropometric indices. Statistical Product for Service Solution (SPSS) version 21was employed in the data analysis. T-test and ChiSquare were used to analyze the relationship among variables and results were presented as frequencies and percentages, means, and standard deviations. Significance was accepted at $\mathrm{p} \leq 0.05$.

Results: Majority (72.4\%) of the respondents were females and 60.0\% were aged 14-16 years. Approximately $50 \%$ of the respondents' fathers and $25.5 \%$ of mothers earned less than $\$ 30,000$ every monthly. Majority (94.8\%) of the respondents skipped breakfast. Little above twenty percent $(20.5 \%)$ of the respondents was mildly stunted while $13.3 \%$ were overweight for their age.

Conclusion: Breakfast skipping and malnutrition in the form of mild to moderate stunting and overweight were prevalent among the study participants suggesting the need for nutrition education to enlighten them on the importance of regular consumption of breakfast meals.
\end{abstract}

Keywords: Skipping breakfast, nutritional status, adolescents

\section{INTRODUCTION}

Breakfast is widely acknowledged to be the most important meal of the day. It can be defined as the first meal eaten in the day before performing daily activities (1). The Department of Agriculture in the United States of America has stated that breakfast meal should contribute at least $10 \%$ of the recommended dietary allowance (RDA) for energy and should provide foods from at least two of the following food groups: grains, low fat dairy products, fruits, vegetables, lean meats, nuts, seeds, and legumes (2).

According to Deshmukh-Taskar (3) habitual consumption of breakfast leads to favourable nutrient intakes including higher intake of dietary fiber, total carbohydrate and lower total fat and cholesterol which helps to ensure that nutrient daily needs by the body are met adequately. Breakfast also makes a large contribution to daily micronutrient intake namely iron, B vitamins (folate, thiamine, riboflavin, niacin, vitamin $\mathrm{B}_{6}$, and vitamin $\mathrm{B}_{12}$ ) and vitamin D are approximately 20-60\% higher in children who regularly eat breakfast compared with those who skip breakfast (4). According to Dialektakou and Vranas (5)consuming breakfast among adolescents can also contribute to maintaining a body mass index (BMI)within the normal range. Sandercock et al. (6) reported that adolescents who do not consume breakfasts are more likely to be less physically active and have a lower cardio-respiratory fitness level.

Nutritional status is the physiological state of an individual, which results from the relationship between nutrient intake and requirement and from the body's ability to digest, absorb and use these nutrients (7). One key factor and determinant of nutritional status is the consumption of adequate amount of food both in terms of quantity and quality. Adolescents who eat breakfast have more favourable weight-related outcomes. They may have lesser likelihood of being chronically obese and decreased risk of obesity because breakfast consumption may result to decrease in the overall energy intake and enhance the quality of diet leading to a reduction of obesity risk (8).

Healthy eating is important because human organs and tissues need proper nutrition to work effectively. Conversely, unhealthy eating pattern may lead to undesirable health outcomes like overweight and obesity. According to Chukwuonye(9) overweight and obesity are among the most common nutritional disorders in developing countries including Nigeria. Nigeria is one of the most populous countries in 
Africa with increasing changes in lifestyle and associated increasing burden of non-communicable diseases (10). This author further showed that overweight and obesity have become epidemic. Overweight puts extra strain on the heart, lungs, bones, muscles and joints and increases the susceptibility to nutrition-related diseases like diabetes mellitus and hypertension. Mozaffarian (11) reported that overweight increases surgical risks, shortens the life span, cause psychosocial problems, and is associated with heart diseases and some form of cancer.

Breakfast skipping has become an increasing trend of the modern lifestyle. There is an increased prevalence of skipping breakfast observed in adolescence (12). Research by Abdel-Hady et al. (13) showed that $28.4 \%$ of adolescents skipped breakfast daily. In a study of adolescent's unhealthy habits associated with meal skipping, daily skipping of breakfast was reported by $53 \%$ of adolescents (14). Skipping of breakfast is considered a worldwide phenomenon among students and is usually associated with various healthcompromising behaviours and unhealthy life styles, such as alcohol, tobacco, and substance use which can lead to poor output and academic performance (15).

During adolescence stage, individuals develop the skills needed to engage and practice behaviours, such as healthy eating that track into later life. Popular trends of breakfast skipping are advertised for weight management; however, conclusive scientific evidence to support these suppositions is lacking (16). Unhealthy diet habit established during adolescence can extend to adulthood. Findings from Australian Bureau of Statistics (17) and McNaughton (18) showed that adults with poor eating behaviours such as low consumption of fruits and vegetables, high consumption of energy-dense snacks and frequent breakfast skipping are eating disorders that may be developed during adolescence stage. The rapid changes in physical growth and psychological development place adolescents as a nutritionally vulnerable group with malign eating behaviour. Given the importance of this life stage in the development of long-term health behaviours and the high prevalence of poor eating behaviours in this population group, there is need to understanding the correlates of breakfast skipping and nutritional status in order to initiate public health strategies and dietary interventions. In the light of this, this study seeks to access the association of skipping breakfast on nutritional status of adolescents (10-19 years) in selected secondary schools in Opi, Nsukka Local Government Area, Enugu State.

\section{MATERIALS AND METHODS}

The study was conducted in Opi, a town in Nsukka Local Government Area of Enugu State in SouthEastern Nigeria. Its geographical coordinates are $6^{\circ}$ $47^{\prime} 0$ " North, $7^{\circ} 26^{\prime} 0^{\prime \prime}$ East. It is the location of a prehistoric archaeological site which contains iron smelting furnaces and slag dated to 750 B.C (19). It has three autonomous communities comprising of about fifty- seven villages.

\section{Subjects}

The study population for this research work were all the selected secondary schools' adolescents in Opi town from JSS2 to SS3 classes. There are 6 secondary schools in Opi out of which four schools were randomly selected and they included: (1) St Mary's Secondary School, Opi, (2) Inland Academy Opi-Nsukka, (3) Comprehensive Secondary Schoool, Opi and (4) Comprehensive Secondary Schoool, Opi-Agu.

\section{Sample and sampling technique}

Sample size for the study was determined using the formula by Yamane (20) as shown below

$$
\begin{aligned}
& \mathrm{n}=\frac{\mathrm{N}}{1+\mathrm{N}(\mathrm{e})^{2}} \\
& \text { Where } \\
& \mathrm{n}=\text { Sample size } \\
& \mathrm{N}=\text { Population size }(616) \\
& \mathrm{e}=\text { level of precision or sample error }(0.05)^{2}
\end{aligned}
$$

Substituting into the equation

$$
\mathrm{n}=\frac{616}{1+616(0.05)^{2}}
$$

$=196$ respondents.

The sample was increased by $5 \%$ to make room for drop outs and recording error.

Five percent $(5 \%)$ of $196=10$ respondents

Sample size $=196+10=206$.

The sample was rounded up to 210 respondents.

Substituting into the equation 35 students were selected from St Mary's Secondary School, Opi with a population of 101 students, 125 respondents were chosen from Inland Academy Opi-Nsukka with a total number of 368 students, 25 respondents were chosen from Comprehensive Secondary School, Opi with a total number 74 students and 25 respondents were also selected from Comprehensive Secondary School, Opi-Agu with a total number of 73 students. The selection of the respondents was based on the proportion of the students found in each school with schools that has the highest number of students having more respondents than their counterparts. This culminated to a gross total of 210 students that participated in the study. This study adopted a cross sectional survey design. A cross-sectional study (also known as prevalence study) is a type of observational study that analyzes data from a population or a representative subset at a specific point in time (21). Multi-stage random sampling was used in selecting the respondents for this research. In stage 1 , four schools were randomly selected from 
the six secondary schools in Opi; in stage 2, random sampling by balloting without replacement was used to select the subjects for the study from the class register of each class. Only students that were physically healthy and indicated interest were used for the study.

\section{Ethical approval/informed consent}

Ethical approval was obtained from the ethical committee of the University of Nigeria Teaching Hospital, Enugu state with the reference number (UNTH/HREC/2021/04/187). Before the actual study, the researcher visited Nsukka Local Government Education Board to obtain the total number of secondary schools in Opi town with their various populations of the students. They also visited the principals of the schools to obtain permission to carry out the study. Two research assistants were trained on how to administer anthropometric measurements and on the correct filling of questionnaires. The researcher explained to adolescents the full information about the study and any question raised was explained and clarified to the understanding of the respondents. Only subjects who consented were recruited for the study. Participants were allowed to withdraw at any stage of the study.

\section{Instruments used for data collection}

The anthropometric indices of the adolescents were taken by the researcher; and questionnaire was filled by the adolescents.

\section{Methods of data collection Questionnaire}

A validated questionnaire was used for the data collection. The questionnaire was structured to elicit information such as the background information, lifestyle characteristics, socio-economic background and dietary habit of adolescents. The questionnaire was self-administered.

\section{Anthropometric measurements}

Anthropometric measurements of adolescents' weight and height were measured based on the standard procedures described by World Health Organization (22). The weight measurement was taken using Hanson's bathroom weighing scale, graduated in kilograms with a capacity of $120 \mathrm{~kg}$. The weighing scale was checked and adjusted if need be to the zero mark. With no shoes on and with minimal clothing, the respondents were made to stand at the centre of the platform of the weighing scale without touching or leaning on anything. With head held erect and arms hanging by the sides, readings were taken to the nearest $0.1 \mathrm{~kg}$.

Height meter graduated in centimetres was used for height measurement. Respondents' height was taken with their shoes removed; both feet parallel to each other and with the heels, buttocks, shoulders and back of head touching the height meter. The head was kept comfortably erect looking straight on a levelled surface. Height measurement was read to the nearest $0.1 \mathrm{~cm}$. BMI is a statistical measure of the body weight of an individual based on his/her weight and height. It is widely used to diagnose weight problem (fatness and thinness) after 2 years of age and in adults indicating whether an individual is underweight, overweight or obese $(23,24)$. Then the relationships of the body mass to the height of the individuals werecalculated using the formula:BMI= weight $(\mathrm{Kg}) /$ height $\left(\mathrm{M}^{2}\right)$. Results were used to compare the level of stunting or thinness of the adolescents in comparison with WHO (25) reference standard.

\section{Statistical analysis}

The data collected was coded and entered into the computer software and analyzed using statistical product for service solution, SPSS version 21. T-test was used to compare group means. Chi square was also used to analyze relationship among variables. Results were presented as frequencies and percentage, means and standard deviations. Significance was accepted at $\mathrm{P} \leq 0.05$.

\section{RESULTS}

Table 1 presents some socio-demographic information of the respondents and respondents' parents. Majority $(72.4 \%)$ of the respondents were females. Most $(60.5 \%)$ of the respondents were aged $15-19$ years. Less than fifty percent $(48.6 \%)$ were in family of between $4-6$ persons. Approximately $52 \%$ of the fathers were farmers while $1.4 \%$ was missionaries. A good number $(44.3 \%)$ of the respondents' mothers were traders while only $1.4 \%$ were missionaries. About $46 \%$ fathers had secondary education while few $(6.7 \%)$ had no formal education. Almost half $(49.5 \%)$ of the respondents' fathers and about 56\% mothers earn less than $\$ 30,000$ monthly. Approximately $36 \%$ of the respondents reported that their family spent between $\$ 2,000$ - $\$ 5,000$ on food weekly while $14.8 \%$ spent less than $\$ 2,000$ on food weekly. 
Table 1: Socio-demographic characteristics of the respondents

\begin{tabular}{|c|c|}
\hline Variable & Frequency (\%) \\
\hline \multicolumn{2}{|l|}{ Sex } \\
\hline Male & $58(27.6)$ \\
\hline Female & $152(72.4)$ \\
\hline Total & $210(100)$ \\
\hline \multicolumn{2}{|l|}{ Age (years) } \\
\hline $10-13$ & $16(7.6)$ \\
\hline $14-16$ & $127(60.5)$ \\
\hline $17-19$ & 67 (31.9) \\
\hline Total & $210(100)$ \\
\hline \multicolumn{2}{|c|}{ Number of people in the household } \\
\hline One to three & $32(15.2)$ \\
\hline Four to six & $102(48.6)$ \\
\hline Greater than six & $76(36.2)$ \\
\hline Total & $210(100)$ \\
\hline \multicolumn{2}{|l|}{ Fathers occupation } \\
\hline Civil servant & $30(14.3)$ \\
\hline Trader & $43(20.5)$ \\
\hline Farmer & $109(51.9)$ \\
\hline Artisan & $25(11.9)$ \\
\hline Missionary & $3(1.4)$ \\
\hline Total & $210(100)$ \\
\hline \multicolumn{2}{|l|}{ Mothers occupation } \\
\hline Civil servant & $16(7.6)$ \\
\hline Trader & $93(44.3)$ \\
\hline Farmer & $81(38.6)$ \\
\hline Artisan & $17(8.1)$ \\
\hline Missionary & $3(1.4)$ \\
\hline \multirow{2}{*}{\multicolumn{2}{|c|}{ Monthly income of father }} \\
\hline & \\
\hline Less than $\$ 30,000$ & $104(49.5)$ \\
\hline N30,000 - $\$ 50,000$ & $61(29.0)$ \\
\hline$\$ 50,000-\$ 100,000$ & $21(10.0)$ \\
\hline Above $\$ 100,000$ & $210(11.4)$ \\
\hline Total & $210(100)$ \\
\hline \multicolumn{2}{|c|}{ Monthly income of mother } \\
\hline Less than $\$ 30,000$ & $118(56.2)$ \\
\hline$\$ 30,000-\$ 50,000$ & $53(25.5)$ \\
\hline$\$ 50,000-\$ 100,000$ & $24(11.4)$ \\
\hline Above $\$ 100,000$ & $15(7.1)$ \\
\hline Total & $210(100)$ \\
\hline \multicolumn{2}{|c|}{ Amount spent on food weekly } \\
\hline Less than $¥ 2,000$ & $31(14.8)$ \\
\hline $\mathrm{N} 2,000-\mathrm{N} 5,000$ & $75(35.7)$ \\
\hline$\$ 5,100-\$ 10,000$ & $57(27.1)$ \\
\hline Above $\$ 10,000$ & $47(22.4)$ \\
\hline Total & $210(100)$ \\
\hline
\end{tabular}

Table 4.2 presents the anthropometric indices of the respondents. Majority $(75.7 \%)$ of the respondents had normal height-for-age while few $(3.8 \%)$ were moderately stunted. The result for BMI-for-age showed that approximately $78 \%$ of the respondents were normal and $9.0 \%$ of them were moderately thin. 
Table 2: Anthropometric indices of the respondents

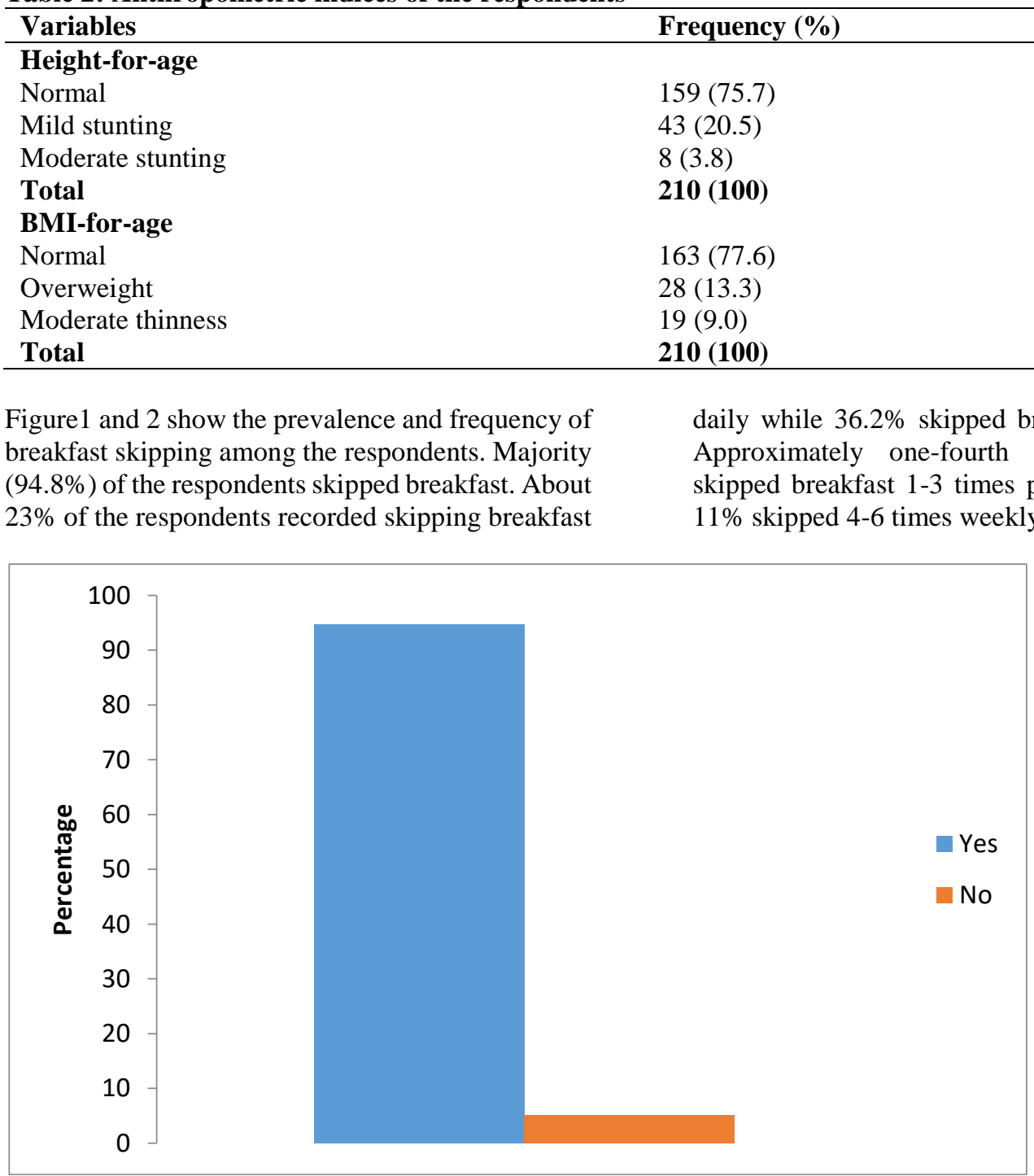

Figure 1: Prevalence of breakfast skipping

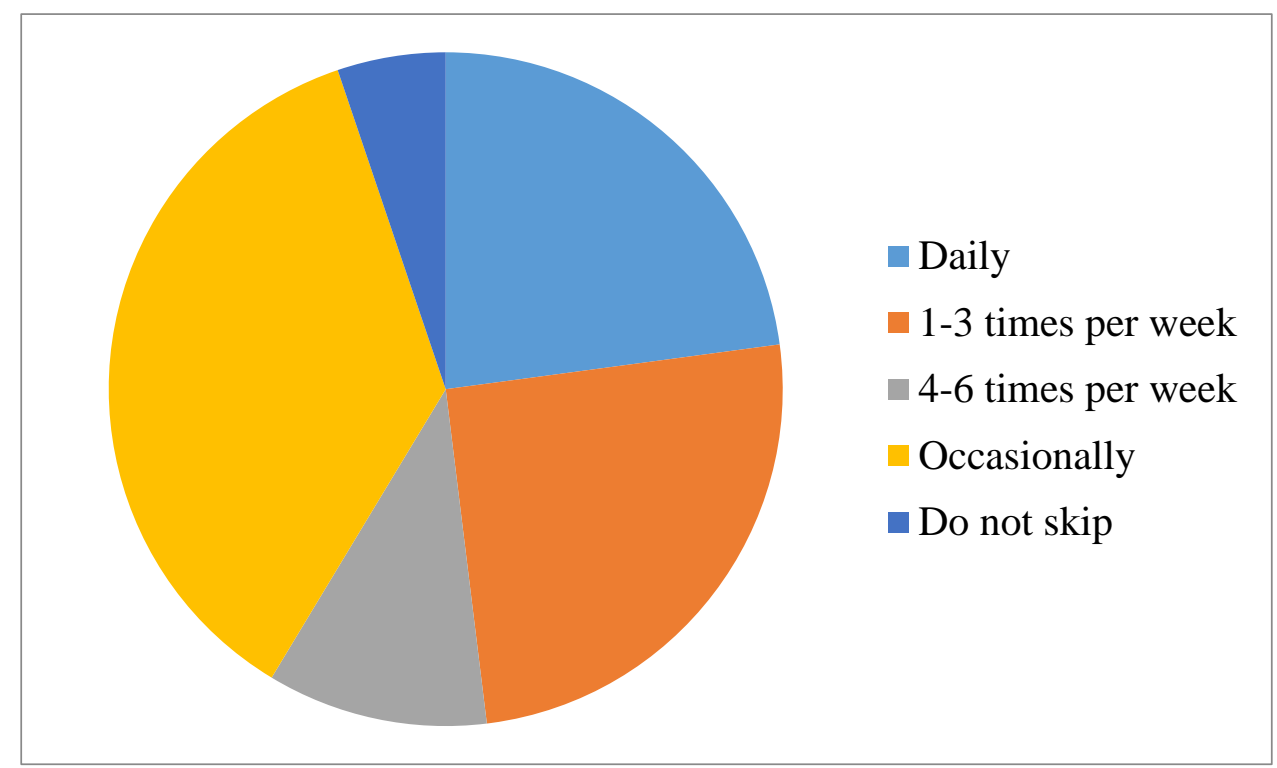

Figure 2: Frequency of breakfast skipping among the respondents 
DOI: https://dx.doi.org/10.4314/jdan.v12i1.8

Table 3 shows the relationship between the frequency of breakfast skipping and anthropometric indices of the respondents.More $(6.2 \%)$ of the respondents that skipped breakfast on daily basis were moderately stunted compared to those that skipped breakfast occasionally $(5.3 \%)$. Whereas none of the respondents that never skipped breakfast had mild stunting, those who skipped breakfast either daily (22.9\%), 1-3 times per week (22.6\%), 46 times per week $(22.7 \%)$ and occasionally $(19.7 \%)$ all manifested different degrees of mild stunting. In terms of BMI-for age, moderate thinness was more (18.8\%) observed among respondents who skipped breakfast daily than those that skipped 1-3 times a week $(9.4 \%)$, 4-6 times a week $(13.6 \%)$ and occasionally $(2.6 \%)$. Overweight was more prevalence $(18.2 \%)$ for each among respondents who skipped breakfast 4-6 times a week and those who never skipped breakfast.

Table 3: Cross-tabulation of frequency of breakfast skipping and anthropometric indices of the respondents

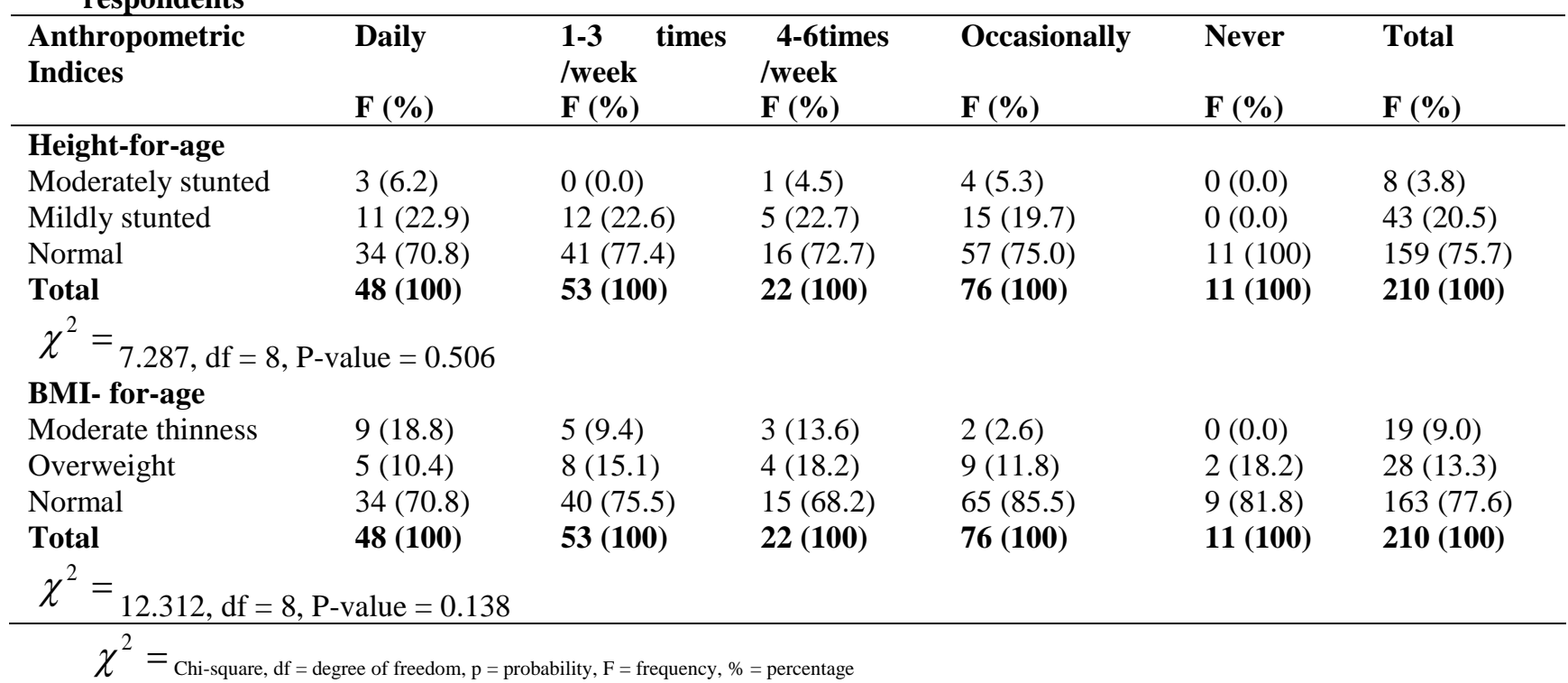

Table 4 presents the reasons for skipping breakfast by the respondents. About one-fifth (21.0\%) skipped because they were not hungry at that moment. Approximately 17\% skipped breakfast because they were too late to school while $7.6 \%$ skipped breakfast because they were too late to school and not hungry at that moment. Only $0.5 \%$ of the respondents skipped breakfast because they were fasting. 
Table 4: Reasons for skipping breakfast by the respondents

\begin{tabular}{|c|c|}
\hline Reasons for skipping & Frequency $(\%)$ \\
\hline Too late to school & $35(16.7)$ \\
\hline Not hungry at that moment & $44(21.0)$ \\
\hline Sick & $2(1.0)$ \\
\hline Don't like the food & $8(3.8)$ \\
\hline No food & $16(7.6)$ \\
\hline Do not want to be overweight/obese & $9(4.5)$ \\
\hline No reason & $11(5.2)$ \\
\hline Too late to school, not hungry at the moment and no food & $4(1.9)$ \\
\hline Too late to school, don't like the food and no food & $8(3.8)$ \\
\hline Too late to school and don't like the food & $12(5.7)$ \\
\hline Too late to school and no food & $3(1.4)$ \\
\hline Too late to school, don't like the food and do not want to be overweight/obese & $2(1.0)$ \\
\hline Too late to school and not hungry at the moment & $16(7.6)$ \\
\hline Too late to school and do not want to be overweight/obese & $5(2.4)$ \\
\hline Too late to school, not hungry at the moment and don't like the food & $5(2.4)$ \\
\hline $\begin{array}{l}\text { Too late to school, not hungry at the moment, no food and do not want to be } \\
\text { overweight/obese }\end{array}$ & $3(1.4)$ \\
\hline Too late to school, not hungry at the moment, do not want to be overweight & $4(1.9)$ \\
\hline Not hungry at the moment and do not want to be overweight/obese & $6(2.9)$ \\
\hline $\begin{array}{l}\text { Not hungry at the moment, don't like the food, no food, do not want to be } \\
\text { overweight/obese }\end{array}$ & $1(0.5)$ \\
\hline $\begin{array}{l}\text { Too late to school, not hungry at the moment, sick, no food \& do not want to be } \\
\text { overweight/obese }\end{array}$ & $1(0.5)$ \\
\hline Not hungry at the moment and no food & $2(1.0)$ \\
\hline Don't like the food and no food & $2(1.0)$ \\
\hline Not hungry at the moment, don't like the food \& do not want to be overweight & $1(0.5)$ \\
\hline Fasting & $1(0.5)$ \\
\hline Too late to school and not hungry at the moment & $2(1.0)$ \\
\hline Not hungry at the moment and don't like the food & $4(1.9)$ \\
\hline Too late to school and not hungry at the moment and don't like the food & $1(0.5)$ \\
\hline Too late to school and sick & $2(1.0)$ \\
\hline Total & $210(100)$ \\
\hline
\end{tabular}

\section{DISCUSSION}

More than half of the adolescents who participated in this study were females. This is similar to a study carried out by Mijinyawaet al. (26) among adolescents in Kano, North western Nigeria, who reported that more than half $(55 \%)$ of their respondents were females. Majority of the respondents were Christians while only a little were traditionalists. This agrees with the study carried out by Omobuwaet al. (27) on assessment of nutritional status of in-school adolescents in Ibadan, Nigeria, who recorded that $83.9 \%$ of their respondents were Christians. This is also in accordance with statistics collected in 2012 by the Nigeria National Bureau of Statistics, which reported that Christian population is located mainly in the middle and the southern part of Nigeria where this present study was carried out. Almost all of the respondents were Igbos. This is due to the fact that Opi town is inhabited majorly by people of Igbo origin. Virtually all the respondents' parents attended formal education (primary, secondary and tertiary schools). This can be attributed to knowledge of the importance of formal education, free basic education and availability of many schools in Enugu State. A good number of the parents were farmers; this agrees with the study carried out in Enugu state by Nicholas and Nnaji (28) which reported that $80.7 \%$ of their respondents had farming as occupation.

Most of the respondents' parents' monthly income was less than $\mathrm{N} 30,000$ which may be attributed to their small-scale farming occupation. A greater number of the respondents fall within the $1 \mathrm{st}-4$ th birth position in their families and most of them had less than 7 persons in their household. This shows that they were majorly from monogamous family which is accepted by Christianity. Nearly half of the bread winners were fathers of the respondents, this shows that fathers generally are saddled with the responsibility of providing for their family. Nearly half of the respondents' mothers prepare food for the family.

Majority of the respondents skipped breakfast. This agrees with a study done by Pendergast etal. (29), which stated that the most frequently skipped main meal is breakfast. It is also in agreement with findings of Aarthi et al. (30) which stated that majority of adolescents skipped breakfast. It also 
agrees with the study of adolescent's unhealthy habits associated with meal skipping by Rodrigues et al. (31) which reported skipping of breakfast by $53 \%$ of adolescents. Moderate thinness was more $(18.8 \%)$ observed among respondents who skipped breakfast daily than those that skipped 1-3 times a week $(9.4 \%)$, 4-6 times a week $(13.6 \%)$ and occasionally $(2.6 \%)$ while overweight was more prevalence $(18.2 \%)$ among respondents who skipped breakfast 4-6 times a week. This agrees with a study of Otuneye, Ahmed, Abdulkarim and Shatima (32) who reported that malnutrition was evidenced by the rate of: stunting (11.2\%), overweight $(12.6 \%)$, obesity $(2.8 \%)$ and wasting (1.7\%) among adolescents' students that skipped breakfast in a correlation study.

The respondents of this study skipped breakfast majorly as a result of not being hungry at that moment and being too late to school (time limit). This agrees with the study by Eldisoky (33) that reported that about half of Saudi Arabia students skipped breakfast because they did not feel hungry at that moment while one-third of them do not have time. It also agrees with the work by Afolabi et al. (34) that reported that $48 \%$ and $19 \%$ of adolescent students skipped breakfast due to lack of time and not being hungry at that moment respectively. Only a negligible number of snacks on fruits and vegetables. This agrees with the work by Racheet al. (35) that reported that adolescents' diets were characterized by a low intake of fruits and green vegetables.

There was low prevalence of stunting among the respondents and low prevalence of thinness. The finding of this study is in contrary to that of Ayoguetal. (36) who reported thinness $31.0 \%$ among adolescents in Nsukka urban area. This difference is likely to stem from different study area, differential nutritional intake and the quality of meals consumed at home. This present study reported no severe stunting, severe thinness and obesity. This could be because this study was carried out in a season when many indigenous foods, fruits and vegetables are available.

\section{Conclusion}

There was low prevalence of malnutrition in form of stunting, thinness and overweight among the respondents. However, moderate thinness was more observed among respondents who skipped breakfast daily than those that skipped 1-3 and 4-6 times a week while overweight was more prevalence among respondents who skipped breakfast 4-6 times a week. Therefore, nutrition education should be employed to enlighten people on the importance of regular consumption of breakfast.

\section{Acknowledgements}

The authors were grateful to the participants for their participation and the Nutrition and Dietetics Department, Faculty of Agriculture, University of Nigeria, for the study conduct.
Conflict of interest: None declared Funding: No funding was received. Author Contribution:

The first author designed and supervised the study. The second author reviewed the manuscript.

The third author collected and statistically analyzed the data.

Data availability: The data for the study is available with the corresponding author on request.

\section{REFERENCES}

1. Carol EO. The Role of Breakfast in Health: Definition and Criteria for a Quality Breakfast. Journal of the Academy of Nutrition and Dietetics. 2014; 114 (12): 8-26.

2. Lauren A, Hasz MA, Lamport D. Breakfast and Adolescent Academic Performance: An Analytic Review of Recent Researches. European Journal of Business and Social Sciences. 2012;114(3): 61-79.

3. Deshmukh-Taskar PR. The relationship of breakfast skipping and type of breakfast consumption with nutrient intake and weight status in children and adolescents: theNational Health and Nutrition Examination Survey 1999-2006. Journal of American Dietetic Association. 2010; 110(6): 86978.

4. Balvin FL, Treviño RP, Echon RM, Garcia-Dominic $\mathrm{O}$, DiMarco N. Association between frequency of ready-to-eat cereal consumption, nutrient intakes, and body mass index in fourth- to sixth-grade lowincome minority children. Journal of Academic Nutrition and Dietetics. 2013; 2(4): 511-519.

5. Dialektakou KD, Vranas PB. Breakfast skipping and body mass index among adolescents in Greece: whether an association exists depends on how breakfast skipping is defined. Journal of American Dietetic Association. (2008); 108: 1517-1525

6. Sandercook GRH, Voss C, Dye L. Association between habitual school-day breakfast consumption, body mass index, physical activity and cardiorespiratory fitness in English school children. European Journal of Clinical Nutrition. 2010; 64: 1086- 1092.

7. Food and Agricultural Organization. (2007). Africa Region Overview of Food Security.

8. Timlin MT, Pereira MA. Breakfast frequency and quality in the etiology of adult obesity and chronic diseases. Nutrition Review. 2007; 65: 268-281

9. Chukwuonye IJ. Prevalence of overweight and obesity in adult Nigerians- a systematic review. Diabetics, metabolic syndrome and obesity. Target and therapy. 2013; 6: 43-47.

10. Dubois L. Breakfast skipping is associated with differences in meal patterns, macronutrient intakes and overweight among pre-school children. Public Health Nutrition Journal. 2009; 12(01): 19-28.

11. Mozaffarian D. Dietary and Policy Priority for Cardiovascular Diseases and Obesity: A Comprehensive Review.Circulation. 2016; 133(2):187-225

12. Sakurai M, Yoshita K, Nakamura K, Takamura T, Nagasawa SY. Skipping breakfast and 5-year changes in body mass index and waist circumference in Japanese men and women. Obesity Science and Practice. 2017; 3: 162-170. 
13. Abdel-Hady EA, El-Gilany AH, Bernadit S. Dietary habits of adolescents' students in Mansoura, Egypt. Pan African Journal. 2014; 16(21): 96-105.

14. Rodrigues PRM, Luiz RR, Monteiro LS, Ferreira MG, Goncalves-Silva RMV, Pereira RA. Adolescents' Unhealthy Eating Habits Are Associated with Meal Skipping. Journal of Nutrition. 2017;42: 114-120.

15. Pendergast F, Livingstone K, Worsley A, McNaughton S. Correlates of Meal Skipping in Young Adults: a Systematic Review. International Journal of Behavior, Nutrition and Physical Activity. 2016;13: 125.

16. Casazza K, Brown A, Astrup A, Bertz F, Baum C, Brown MB, Dawson J, Durant N, Dutton G, Fields DA. Weighing the evidence of common beliefs in obesity research. Critical Review in Food Science and Nutrition. 2015; 55: 2014-2053.

17. Australian Bureau of Statistics. Australian Health Survey. Nutrition First Results -Foods and Nutrients, 2011-12. Canberra: Australian Government; 2014:

18. McNaughton SA. An index of diet and eating patterns is a valid measure of diet quality in an Australian population. Journal of Nutrition. 2008; 138(1): 86-93.

19. Agu CS, Opata CC. Iron Technology and Political Power: example from the iron smelting belt of Nsukka Area, Enugu state, south-eastern Nigeria. Research on Humanity and Social Sciences. 2012; 29.

20. Yamane T. Statistics: An Introductory Analysis, $2^{\text {nd }}$ Ed., New York: Harper and Row; 1967.

21. Nikolaos P. Statistics and Research Design. American Journal of Orthodoritics Dentofacial Orthopedics. 2014; 146 (1): 127-129.

22. World Health Organization. Physical status: the use and interpretation of anthropometry. Report of a WHO Expert committee, WHO Technical Report series. (1995; 854: Geneva, Switzerland

23. Academy for Nutrition and Dietetics (AND). Pocket Guide for International Dietetics \& Nutrition Terminology (IDMT) Reference Manual: Standardized Language for the Nutrition Care Process ( $4^{\text {th }}$ ed.). Chicago, USA; 2013.

24. Ibeanu V, Okeke E, OnyechiU, Ejiofor U. Assessment of anthropometric indices, iron and zinc status of preschoolars in peri-urbancommunities in south east Nigeria. International Journal of basic \& applied Nutrition sciences. 2012; 12:5.

25. World Health Organization. Waist Circumference and Waist - Hip Ratio, Body Mass Index: Report of a WHO Expert Consultation. Geneva. 2007.

26. Mijinyawa MS, Yusuf SM, Gezawa ID, Musa BM, Uloko AE. Prevalence of thinness among adolescences in Kano, Northwestern Nigeria. National Journal of Basic and Clinical science. 2014; 11(1): 24-29.

27. Omobuwa O, Alebiosu OC. Awareness of diabetes amongst undergraduate in Nigerian university, south west Nigeria. Sahel Medical Journal. 2014; 17(1): 29-33.

28. Nicholas $O$, Nnaji $C$. The role of extention in agricultural adaptation to climate change in Enugu State, Nigeria. Journal of Agricultural Extension and Rural Development. 2010; 3(3): 42-50.

29. Pendergast F, Livingstone K, Worsley A, McNaughton S. Correlates of Meal Skipping in

\section{DOI: https://dx.doi.org/10.4314/jdan.v12i1.8}

Young Adults: a Systematic Review. International Journal of Behavior, Nutrition and Physical Activity. 2016;13: 125

30. Aarthi M, Priya V, Gayathri R. Awareness on the effect of skipping breakfast among adolescents. Drug Intervention Today. 2018; 10(6): 33-36.

31. Rodrigues PRM, Luiz RR, Monteiro LS, Ferreira MG, Goncalves-Silva RMV, Pereira RA. Adolescents' Unhealthy Eating Habits Are Associated with Meal Skipping. Journal of Nutrition. 2017;42: 114-120.

32. Otuneye AT, Ahmed PA, Abdulkarim AA, Aluko OO, Shatima D.R. Relationship between dietary habit and nutritional status among adolescents in Abuja Municipal Area Council of Nigeria. Journal of Paediatrics, 2017; 44(3): 128-135.

33. Eldisoky ST. Interactive relation between dietary habits and spread of malnutrition diseases. Annual of Agric Science. 2003; 48: 663-675.

34. Afolabi WAO, Towobola SK,Oguntona CRS, Olayiwola LO. Pattern of Food Consumption and Contribution to Energy Intake Among Nigerian Students. International Journal of Education and Research. 2013; 1(5): 1-10.

35. Rache H, Imma V, Du-Toit L. Development of a food knowledge test for first-year students at a university of technology in the Western Cape, South Africa. Journal of Family Economy and Consumption Science. 2014; 42: 28-32.

36. Ayogu NB, Nnam M, Ibemesi O, Okechukwu F. Prevalence and factors associated with anthropometric failure, vitamin A and iron deficiency among adolescents in a Nigerian urban community. Journal of African Health Sciences. 2016; 16(2): 389-398. 